\title{
The evolution of an active solitary idiopathic choroiditis (focal scleral nodule): a case report of the natural course and a review of the literature
}

\author{
Yilin Feng ${ }^{\dagger}$, Christopher D. Conrady ${ }^{\dagger}$ and Hakan Demirci ${ }^{*}$
}

\begin{abstract}
Background: To describe the clinical course of an active solitary idiopathic choroiditis (focal scleral nodule) that nearly resolved over six weeks without intervention.

Case presentation: An 18-year-old man presented to the emergency department with headaches and new onset central scotoma in the right eye. Visual acuity was 20/20 in both eyes. Fundus examination revealed an amelanotic choroidal lesion with associated shallow subretinal fluid. It measured $6.1 \times 6.3 \times 1.4 \mathrm{~mm}$ on A- and B-scan. Evaluation for systemic inflammatory and infectious diseases was negative. A week later, the lesion remained stable, and a month later, there was improvement of the lesion with a decrease in size on OCT and exam and resolution of the subretinal fluid suggesting that the lesion had become inactive.

Conclusions: Solitary idiopathic choroiditis (Focal scleral nodule) is a rare condition characterized by inflammatory granulomatous reaction. This case report sheds light on the unknown natural course of a solitary idiopathic choroiditis (focal scleral nodule).
\end{abstract}

Keywords: Choroidal granuloma, Granuloma, Ocular mass, Solitary idiopathic choroiditis, Focal scleral nodule

\section{Background}

A focal scleral nodule (FSN), previously referred to as solitary idiopathic choroiditis (SIC) and unifocal helioid choroiditis, is characterized by an inflammatory granulomatous reaction in the sclera and/or choroid in the absence of an underlying systemic inflammatory disease [1-3]. It is a rare condition found more commonly in white females between the ages of 20 and 50 and where approximately a third of patients are asymptomatic at time of diagnosis [2].

\footnotetext{
* Correspondence: hdemirci@med.umich.edu

${ }^{+}$Yilin Feng and Christopher D. Conrady contributed equally to this work. Department of Ophthalmology and Visual Sciences, Kellogg Eye Center, University of Michigan, 1000 Wall Street, Ann Arbor, MI 48105, USA
}

Current management recommendations of FSN suggest monitoring of inactive lesions and either close observation or treatment with systemic corticosteroids for active lesions [2]. The natural history of an FSN has not been well documented, and to our knowledge, there are no specific case reports of FSN in the literature that describe the evolution of an active lesion to its inactive state. Here, we describe the clinical course of an active FSN that became inactive over six weeks without intervention.

\section{Case presentation}

An 18-year-old otherwise healthy, white male presented to the emergency department with headaches and new onset central scotoma in the right eye of six days

(C) The Author(s). 2021 Open Access This article is licensed under a Creative Commons Attribution 4.0 International License, which permits use, sharing, adaptation, distribution and reproduction in any medium or format, as long as you give appropriate credit to the original author(s) and the source, provide a link to the Creative Commons licence, and indicate if changes were made. The images or other third party material in this article are included in the article's Creative Commons licence, unless indicated otherwise in a credit line to the material. If material is not included in the article's Creative Commons licence and your intended use is not permitted by statutory regulation or exceeds the permitted use, you will need to obtain permission directly from the copyright holder. To view a copy of this licence, visit http://creativecommons.org/licenses/by/4.0/ The Creative Commons Public Domain Dedication waiver (http://creativecommons.org/publicdomain/zero/1.0/) applies to the data made available in this article, unless otherwise stated in a credit line to the data. 
duration. He had a history of strabismus and amblyopia of the left eye as a child that had been surgically corrected twice. On initial presentation, his visual acuity was 20/20 in both eyes and anterior segment examination was unremarkable. Fundus exam at that time of the right eye demonstrated a round-shaped, amelanotic choroidal lesion, with associated shallow subretinal fluid (SRF) along the superior arcade. Optical coherence tomography (OCT) of the macula confirmed a hypointense choroidal mass with overlying outer retinal changes and SRF extending to the fovea (Fig. 1a). Due to the lack of systemic symptoms, a focused laboratory evaluation for infectious (syphilis, Lyme disease, Bartonella, toxocariasis, toxoplasmosis, and tuberculosis) and inflammatory diseases (sarcoidosis, and granulomatosis with polyangiitis) was unrevealing. The lesion was observed due to the patient's good overall visual acuity and given the presumptive diagnosis of FSN. A week later and symptoms unchanged, diagnostic A- and B-scan ultrasonography demonstrated a dome-shaped acoustically-solid scleral/ choroidal lesion with overlying SRF and intrinsic vascularity measuring $6.1 \times 6.3 \times 1.4 \mathrm{~mm}$, consistent with examination and OCT findings and stable from prior (Figs. 1b, 2a and 3a). Six weeks later, the symptoms of the patient had improved, the thickness of the lesion was relatively stable on A- and B-scan but improving on OCT, the SRF fluid had resolved, and an orange halo had formed around the lesion, suggesting that the lesion had become inactive (Figs. 1c, 2b and 3b).

\section{Discussion and conclusions}

FSN is usually diagnosed based on detailed patient medical history, systemic laboratory evaluation for inflammatory and infectious etiologies, clinic features, such as lack of inflammatory cells in anterior chamber and vitreous, and ocular imaging findings such as absence of contact sign as reported in choroidal granulomas [4].

We herein describe a case of an 18-year-old, symptomatic male who presented with FSN. His FSN became inactive over the course of six weeks without intervention. Although this is a report of a single patient, we describe the natural course of an active FSN and its spontaneous resolution, which has not specifically been described in the literature. Due to the lack of formal guidelines on the treatment of FSN, the clinical course of patients who are followed longitudinally, as in our

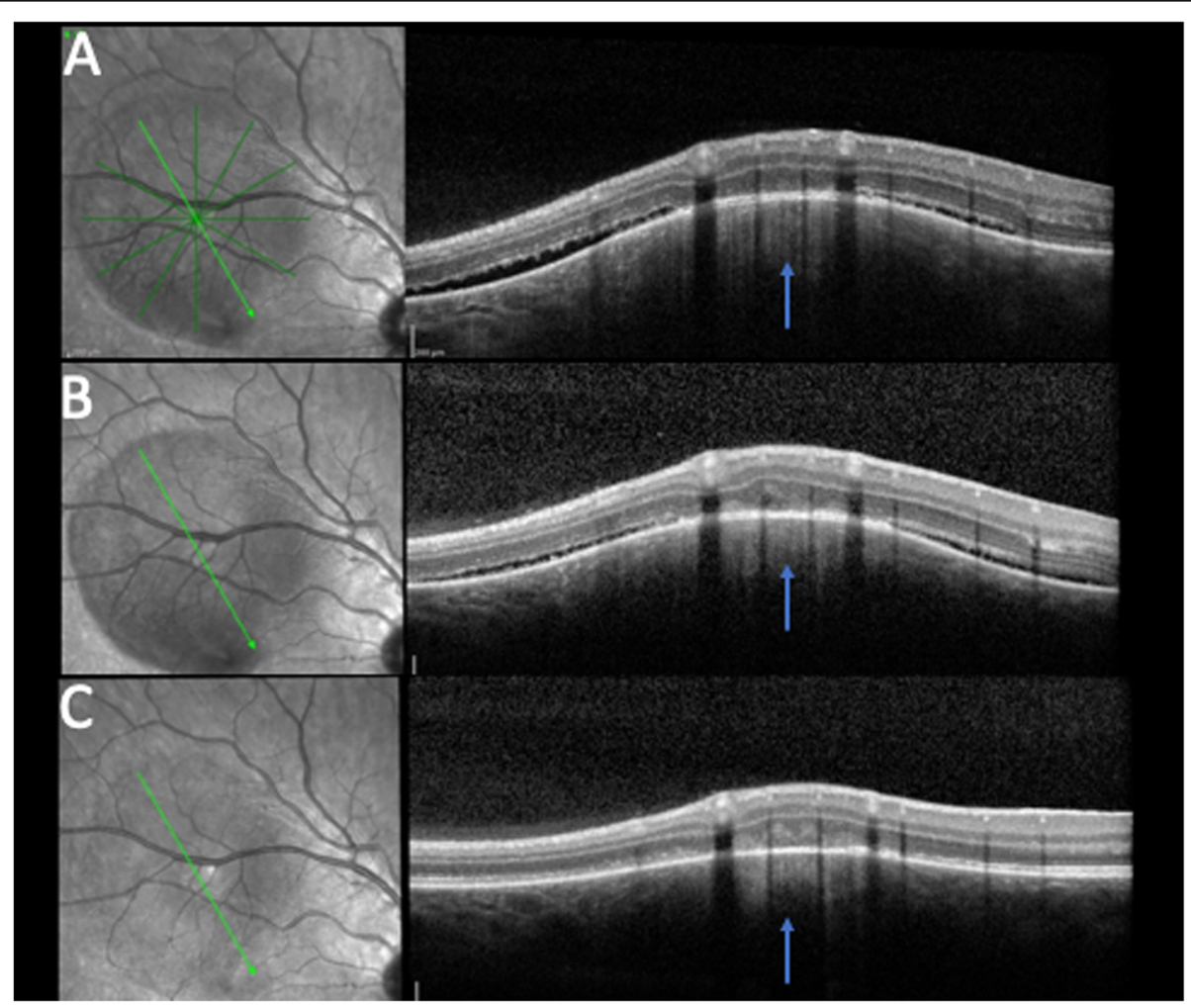

Fig. 1 OCT findings at presentation, one week, and six weeks later. a OCT demonstrating SRF surrounding the elevated, choroidal lesion at presentation with a "contact sign" (retained attachment between retinal pigment epithelium and neurosensory retina over the granuloma) [4] and remained relatively unchanged one week later except for a mild improvement in the amount of subretinal fluid (b). c Six weeks later, the surrounding subretinal fluid had resolved and the choroidal lesion was much flatter. Blue arrow, lesion 


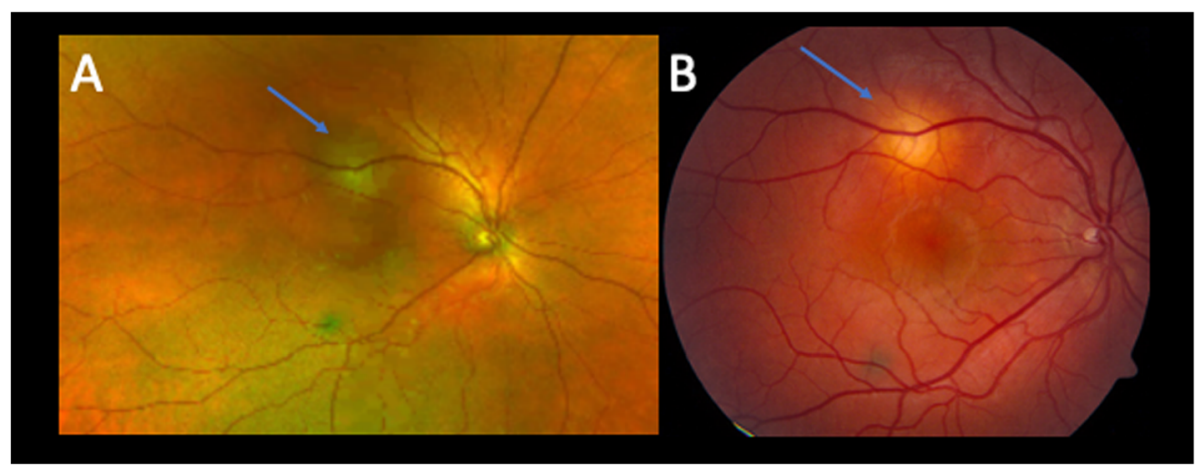

Fig. 2 Fundus photographs at one week and six weeks later.a Fundus photograph showing a yellowish choroidal lesion with surrounding subretinal fluid one week after presentation. b Six weeks later, the subretinal fluid had resolved, and an orange halo had formed around the lesion. Blue arrow, lesion

patient's case, can provide valuable information to providers who encounter this rare condition.

In the largest retrospective study of FSN in the literature by Shields et al.., they reviewed sixty patients with both active and inactive lesions. In their study, the lesion remained stable in $60 \%$ of the patients, improved in $37 \%$, and recurred in $3 \%$ during a six-month to twentyfive-year follow up period (mean of 24 months) [2]. However, the results of this study were not stratified into active and inactive lesions, so the clinical course of an active lesion was still unclear. Furthermore, for the lesions that demonstrated improvement on follow up, the duration and course of improvement was also unclear due to the variable follow up length [2]. Moreover, $27 \%$ of the patients in the study had received prior treatment, further confounding the study outcomes [2]. The authors of the study acknowledged the variation of patient treatments, stating that "it was impossible to determine the overall response to treatment [2]." However, they did suggest that active lesions generally respond favorably to systemic corticosteroids but can also improve without treatment. They also advised that inactive lesions should be monitored and that most remain quiescent over time [2].

Although there have been other reported cases of FSN, those reports also do not provide clarity regarding the natural course of an active lesion. Moreover, the authors frequently do not identify whether the presenting lesion is active or inactive. As seen in our case, the active lesion presents as a dull-yellow lesion with an ill-defined margin, associated with yellow intraretinal exudation, localized subretinal fluid, retinal vascular dilation, or focal retinal hemorrhages. In the original report of FSN by Hong et al., a total of six patients were described, five of which received systemic corticosteroid therapy, and the sixth patient's lesion was observed and remained stable after one year [1]. While this study originally described the entity, the use of systemic corticosteroids made it impossible to understand the natural history of the lesions [1]. In the report by Kohne et al.., they described a

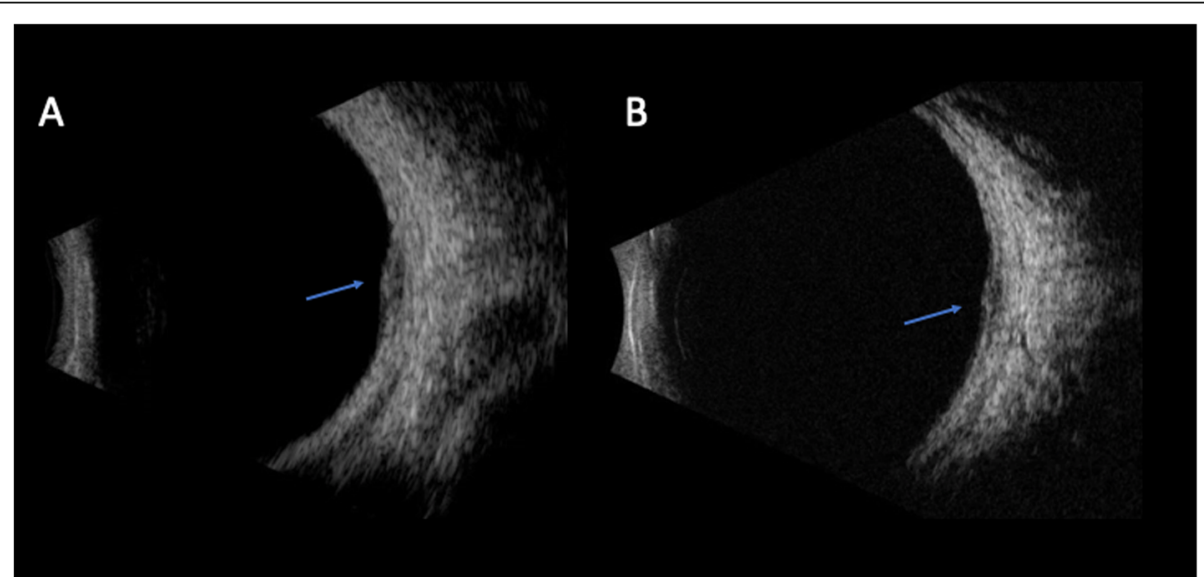

Fig. 3 B-scan ultrasonography at one week and six weeks after presentation.a-b B-scan identified a small, dome-shaped fundus lesion measuring $1.4 \mathrm{~mm}$ (height) $\times 6.1 \mathrm{~mm} \times 6.3 \mathrm{~mm}$ one week after presentation (a) and remained relative unchanged six weeks later (b). Blue arrow, lesion 
patient whose lesion mildly improved with no intervention six months later, but the lesion was likely inactive at presentation due to lack of surrounding fluid and distinct margins seen in the later phases of FA, features of activity [5]. Other case reports of FSN in the literature do not follow the patients longitudinally or present patients who have already received treatment making any extrapolation of natural history of the lesions impossible [6-8]. Understanding the evolution of active lesions can provide prognostic value and contribute to the recommendations of future treatment guidelines of FSN as we hope this case report does; however, as with any case report, this represents only a single case and broad generalizations cannot be drawn. Little is known about this entity, and recently, even the anatomical focus of inflammation has been re-defined [3].

\section{Abbreviations}

FA: Fluorescein angiogram; FSN : Focal scleral nodule; mm: Millimeter; OCT: Optical coherence tomography; SIC: Solitary idiopathic choroiditis; SRF: Subretinal fluid

\section{Acknowledgements}

We would like to thank the ultrasound and imaging staff at Kellogg Eye Center for their images and expertise.

\section{Disclosures}

The following authors have no financial disclosures: YF, CDC, and HD.

\section{Authors' contributions}

$Y F, C D C$, and $H D$ analyzed and interpreted the patient data and were major contributors in writing the manuscript. All authors read and approved the final manuscript. All authors attest that they meet the current ICMJE criteria for Authorship and wrote and edited the manuscript as detailed above.

\section{Funding}

This case report was supported by Richard N. and Marilyn K. Witham Professorship. CDC was supported in part by the Heed Ophthalmic

Foundation.

\section{Availability of data and materials}

Data sharing is not applicable to this article as no datasets were generated or analyzed during the current study.

\section{Declarations}

\section{Ethics approval and consent to participate}

The need for ethics approval was waived by the University of Michigan.

\section{Consent for publication}

Consent to publish the case report was obtained from the patient both with written and verbal consent.

\section{Competing interests}

The authors declare that they have no competing interests.

Received: 1 December 2020 Accepted: 1 March 2021

Published online: 09 March 2021

\section{References}

1. Hong PH. Unifocal helioid choroiditis. Arch Ophthalmol. 1997:115(8):1007.

2. Shields JA, Shields CL, Demirci H, Hanovar S. Solitary idiopathic choroiditis: The Richard B. Weaver lecture. Arch Ophthalmol. 2002;120:9.

3. Fung AT, Waldstein SM, Gal-Or O, Pellegrini M, Preziosa C, Shields JA, et al. Focal scleral nodule: a new name for solitary idiopathic choroiditis and unifocal helioid choroiditis. Ophthalmology. 2020. [cited 2020 Aug 30];
Available from:http://www.sciencedirect.com/science/article/pii/S016164202 0303961

4. Salman A, Parmar P, Rajamohan M, Vanila CG, Thomas PA, Jesudasan CAN. Optical coherence tomography in choroidal tuberculosis. Am J Ophthalmol. 2006;142(1):170-2.

5. Kohne KD, Malinovsky VE, Gao H. Solitary idiopathic choroiditis. Optom St Louis Mo. 2007;78(4):176-80

6. Kotsolis Al, Yannuzzi LA. Solitary idiopathic choroiditis with choroidal neovascularization. Retin Cases Brief Rep. 2009:3(4):395-7.

7. Monteiro S, Andrews R, Sagoo M. Solitary idiopathic choroiditis. Case Rep Ophthalmol. 2014:5(1):1-5.

8. Fung AT, Kaliki S, Shields CL, Mashayekhi A, Shields JA. Solitary idiopathic choroiditis: findings on enhanced depth imaging optical coherence tomography in 10 cases. Ophthalmology. 2013;120(4):852-8.

\section{Publisher's Note}

Springer Nature remains neutral with regard to jurisdictional claims in published maps and institutional affiliations.
Ready to submit your research? Choose BMC and benefit from:

- fast, convenient online submission

- thorough peer review by experienced researchers in your field

- rapid publication on acceptance

- support for research data, including large and complex data types

- gold Open Access which fosters wider collaboration and increased citations

- maximum visibility for your research: over $100 \mathrm{M}$ website views per year

At BMC, research is always in progress.

Learn more biomedcentral.com/submissions 